\title{
The Most Likely Sites for Hydrocarbon Prospects in Some Part of Sokoto Lower Basin, North-Western, Nigeria
}

\author{
*Corresponding Author \\ Kamba AH \\ Article History \\ Received: 26.06.2019 \\ Accepted: 20.07.2019 \\ Published: 30.07 .2019
}

Kamba $\mathrm{AH}^{1 *}$ and Bonde DS²

${ }^{1}$ Department of Science Education, Kebbi State University Science and Technology, Aliero, Nigeria

2Department of Physics, Kebbi State University of Science and Technology, Aliero, Nigeria

\begin{abstract}
Geophysical investigations to determine the most probable sites for hydrocarbon prospects in lower Sokoto Basin was carried out using the total magnetic field values that were obtained by digitizing the contour maps of the basin, which was used to produce the composite map of the area. The lower Sokoto Basin is situated between latitudes $10^{\circ} .50^{\prime \prime} \mathrm{N}$ to $11^{\circ} .50^{\prime \prime} \mathrm{N}$ and longitude $4{ }^{\circ "} \mathrm{E}$ to $5^{\circ} \mathrm{E}$. Spectral depth analysis were carried out on the residual magnetic map to study the subsurface geological features of the basin. The results of the spectral studies indicate an increase in sedimentation southwards with several depressions on the basement rock. Two prominent magnetization layers of depths varying from $0.589 \mathrm{~km}$ to $1.249 \mathrm{~km}$ and $2.506 \mathrm{~km}$ to $3.174 \mathrm{~km}$ were observed. The highest sedimentary thickness of $3.2 \mathrm{~km}$ encountered using spectral depth analysis is in the vicinities of Konkoso (sheet no: 117). These areas, where higher sedimentary thicknesses are encountered in this study, are the most probable sites for prospect of hydrocarbon accumulation in the area.
\end{abstract}

Keywords: geophysical investigation; composite map; sedimentary thickness; anomalies

\section{INTRODUCTION}

The Earth and its contents have long been of concern to mankind. Man has tried to unravel its complexity and delve into its origin via various geophysical methods. The subsurface has been of particular concern to geoscientists, who seek to investigate it using diverse means, some for the purpose of having knowledge, while others do it for exploration of economic resources such as minerals and hydrocarbons. With the advances in technology and the need to have a clearer picture of the Earth subsurface and its contents, the Earth scientists have deemed it necessary to utilize the properties associated with Earth's interior. Geophysics involves the application of physical principles and quantitative physical measurements in order to study the Earth's interior. The analysis of these measurements can reveal how the earth interior varies both vertically and laterally, the interpretation of which can reveal meaningful information on the geological structures beneath [1]. By working at different scales, geophysical methods may be applied to a wide range of investigations from studies of the entire earth to exploration of a localized region of the upper crust for engineering or other purposes [2]. A wide range of geophysical methods exist for each of which there is an operative physical property to which the method is sensitive. The type of physical property to which a method responds clearly determines its range of application. For instance, magnetic method is very suitable for locating buried magnetic ore bodies because of their magnetic susceptibility. Similarly, seismic and electrical methods are suitable for locating water table, because saturated rock may be distinguished from dry rock by its higher seismic velocity and higher electrical conductivity [2]. In exploration for subsurface resources, the geophysical methods are capable of detecting and delineating local features of potential interest. Geophysical methods for detecting discontinuities, faults, joints and other basement structures, include the following: magnetic, seismic, resistivity, electrical, potential field, well logging, gravity, radiometric, thermal etc [3]. Some geophysical methods such as gamma- ray spectrometry and remote sensing measure surface attributes; others, such as thermal and some electrical methods are limited to detecting relatively shallow subsurface geological features. Most economic minerals, oil, gas, and groundwater lie concealed beneath the Earth surface, thus hidden from direct view. The presence and magnitude of these resources can only be ascertained by geophysical investigations of the subsurface geologic structures in the area.

Copyright @ 2019: This is an open-access article distributed under the terms of the Creative Commons Attribution license which permits unrestricted use, distribution, and reproduction in any medium for non commercial use (NonCommercial, or CC-BY-NC) provided the original author and source are credited. 


\section{MATERIALS AND METHODS \\ Data Acquisition}

The study area forms part of lower Sokoto sedimentary basin in northwest Nigeria and is covered by four (4) aeromagnetic maps. These maps were obtained from the Nigerian Geological Survey Agency (NGSA). The Agency carried out an airborne magnetic survey of substantial part of Nigeria between 1974 and 1980. The data were collected at a nominal flight altitude of $152.4 \mathrm{~m}$ along N-S flight lines spaced approximately $2 \mathrm{~km}$ apart. The magnetic data collected were published in form of contour lines on $1 / 2$ degree aeromagnetic maps on a scale of 1:100,000. The magnetic values were plotted at $5 \mathrm{nT}$ (Nano Tesla) interval. The maps were numbered, and named according to the places covered and coordinates (longitude and latitudes) were written for easy reference and identification. The country was divided to a total of 340 sheets. The actual magnetic values were reduced by 25,000 gammas before plotting the contour map. This means that the value of 25,000 gammas should be added to the contour values so as to obtain the actual magnetic field at a given point. A correction based on the International Geomagnetic Reference Field, (IGRF,) and epoch date January 1, 1974 was included in all the maps. The visual interpolation method that is the method of digitizing on grid layout was used to obtain the data from field intensity aeromagnetic maps covering the study area. The data from each digitized map were recorded in a 19 by 19 coding sheet which contains the longitude, latitude and the name of the town flown and the sheet number. The present study area covered four (4) maps numbered 95, 96,117,118. Surfer 11 software was used to import the dataset consisting of three columns (longitude, latitude and magnetic values). The composite map was produced using Oasis Montaj version 7.1.software

\section{Regional-residual Separation}

Magnetic data observed in geophysical surveys comprises of the sum of all magnetic fields produced by all underground sources. The composite map produced using such data, therefore contains two important disturbances, which are different in order of sizes and generally super-imposed. The large features generally show up as trends, which continue smoothly over a considerable distance. These trends are known as regional trends. Super-imposed on the regional field, but frequently camouflaged by these, is the smaller, local disturbances which are secondary in size but primary in importance. These are the residual anomalies. They may provide direct evidence of the existence of the reservoir type structures or mineral ore bodies.

\section{Production of Regional and Residual Maps}

The residual magnetic field of the study area was produced by subtracting the regional field from the total magnetic field using the Polynomial fitting method. The computer program Aerosupermap was used to generate the coordinates of the total intensity field data values. This super data file, for all the magnetic values was used for production of composite aeromagnetic map of the study area using Oasis Montaj software version 7.1 A program was used to derive the residual magnetic values by subtracting values of regional field from the total magnetic field values to produce the residual magnetic map and the regional maps.

\section{Spectral Depth Analysis}

Determination of depths to buried magnetic rocks is among the principal applications of an aeromagnetic data. The depths are commonly computed from measurement made on the widths and slopes of an individual anomaly of the aeromagnetic profiles. The statistical approach has been found to yield good estimates of mean depth to basement underlying a sedimentary basin $[4,5]$. Spector [6] and Spector and Grant [7] developed a depth determination method which matches two dimensional power spectral calculated from gridded total magnetic intensity field data with corresponding spectral obtained from a theoretical model. For the purpose of analyzing aeromagnetic data, the ground is assumed to consist of a number of independent ensembles of rectangular, vertical sided parallelepiped, and each is ensemble characterized by a joint frequency distribution for the depth (h) and length (b) and depth extent $(\mathrm{t})$. In this work, the characteristics of the residual magnetic field are studied using statistical spectral methods. This is done by first transforming the data from space to the frequency domain and then analyzing their frequency characteristics. In the general case, the radial spectrum may be conveniently approximated by straight line segments, the slopes of which relate to depths of the possible layers, $[7,4]$. The residual total magnetic field intensity values are used to obtain the two dimensional Fourier Transform, from which the spectrum is to be extracted from the residual values $T(x, y)$ consisting of $M$ rows and $N$ columns in $X-Y$. The two dimensional Fourier transforms is obtained as given in equation (2.1) above. The evaluation is done using an algorithm that is a two dimensional extension of the fast Fourier transform [8]. Next, the frequency intervals are subdivided into sub-intervals, which lie within one unit of frequency range. The average spectrum of the partial values together constitutes the redial spectrum of the anomalous field $[4,9,5]$. The logarithm of the energy values versus frequency on a linear scale was plotted and the linear segments located; the use of Discrete Fourier Transform introduced the problem of aliasing and the truncation effect (or Gibbs phenomenon). Aliasing was reduced by the digitizing interval used in the study. Three or two linear segments could be seen from the graphs. The first points on the frequency scale was ignored because the low frequency components in the energy spectrum are generated from the deepest layers whose locations are most likely in errors. Each linear segment groups points due to anomalies caused by bodies occurring within a particular depth. If the $z$ is the mean depth of the layer, the depth factor for this ensemble of anomalies is exp (-2zk). Thus the logarithmic plot of the radial spectrum would give a straight line whose slope is $-2 z$. The mean depth of the burial ensemble is thus given as

$$
Z=-\frac{m}{2}
$$


Where $(\mathrm{m})$ is the slope of the best fitting straight line Equation 2.1 can be applied directly if the frequency unit is in radian per kilometre. If however, the frequency unit is in circle per kilometre, the corresponding relationship can be expressed as

$$
Z=-\frac{m}{4 \pi}
$$

\section{ANALYSIS AND RESULTS \\ Total Magnetic Intensity Map}

The colours shaded total magnetic intensity (TMI \& map of the study area is shown in Figure 4.1 while the contour map is shown in Figure 4.2. The colours shaded TMI map of the study area can be divided into three main sections, though minor depressions exist scattered all over area. The northern part of study area is predominantly characterized by high magnetic intensity values represented by pink-red colours, whereas the southern part is dominated by low and moderate TMl values represented by blue and green color respectively. The northern and southern parts of the study area were observed to be separated by a zone characterized by medium TMI values area depicted by yellow-orange colours. These high TMI values, which dominate the northern part of the study area, were interpreted to be caused probably by near surface igneous rocks of high values of magnetic susceptibilities. The low amplitudes (i.e. TMl values) where interpreted to be caused by sedimentary rocks of low magnetic susceptibilities or altered basement rocks. While the high TMI values were due to igneous and crystalline basement rocks. The contour map of the TMI values shows that the southeastern part (SE) and lower portion of the northeastern part (NE) are predominantly associated with short wavelength anomalies while the rest portion of the study area is dominated by long wavelength anomalies. The trends of the anomalies were observed along (NE-W), (E.W, N.S) and (NW-SW) directions.

\section{Regional Magnetic Intensity Map.}

The regional magnetic intensity map of the study area (Figure 3. 2) produced using Oasis Montaj version 7.1 is as shown below. The regional magnetic values ranges from 7860 nano Tesla to 8160 nano Tesla and the values decreases from south to north indicating there is a fill of sediments more in the southern part of the area than in the northern part of the study area. The result of regional indicates deeper sedimentation in the south than in the northern part of the study area.

\section{Residual Magnetic Intensity Map}

Figure.3.3 is the residual magnetic intensity map of the study area. The residual map is characterized with positive and negative magnetic susceptibility values. The pink and red colour represents the high positive values while the blue colour represents high negative values. The pale-green and yellow colour represent the lower negative and lower positive magnetic values respectively. The magnetic intensity values ranges from -10 nano Tesla to 40 nano Tesla. Negative magnetic intensity values are more predominant in the southeast section of the study area while the northwest has more of positive magnetic intensity values. Northeast Southwest trends are observed in the north central part of the TMI map. The blue color in the southeast indicating the area of higher sedimentation around sheet 117 (konkoso) in the study area with the prospect of hydrocarbon accumulation.

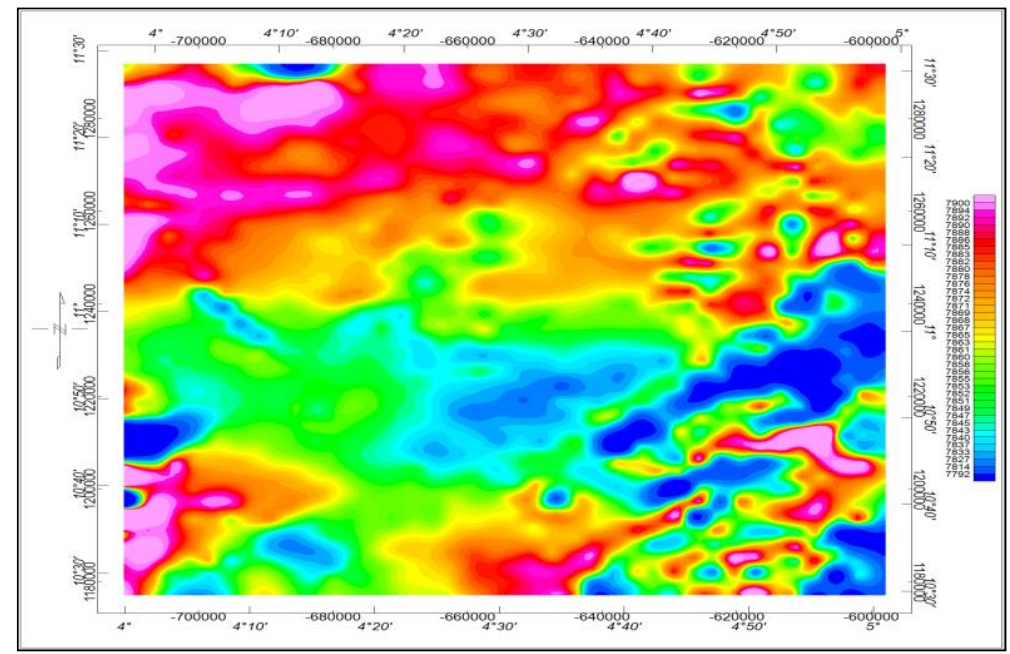

Fig-3.1: Total Magnetic Intensity Map of the Study Area. 


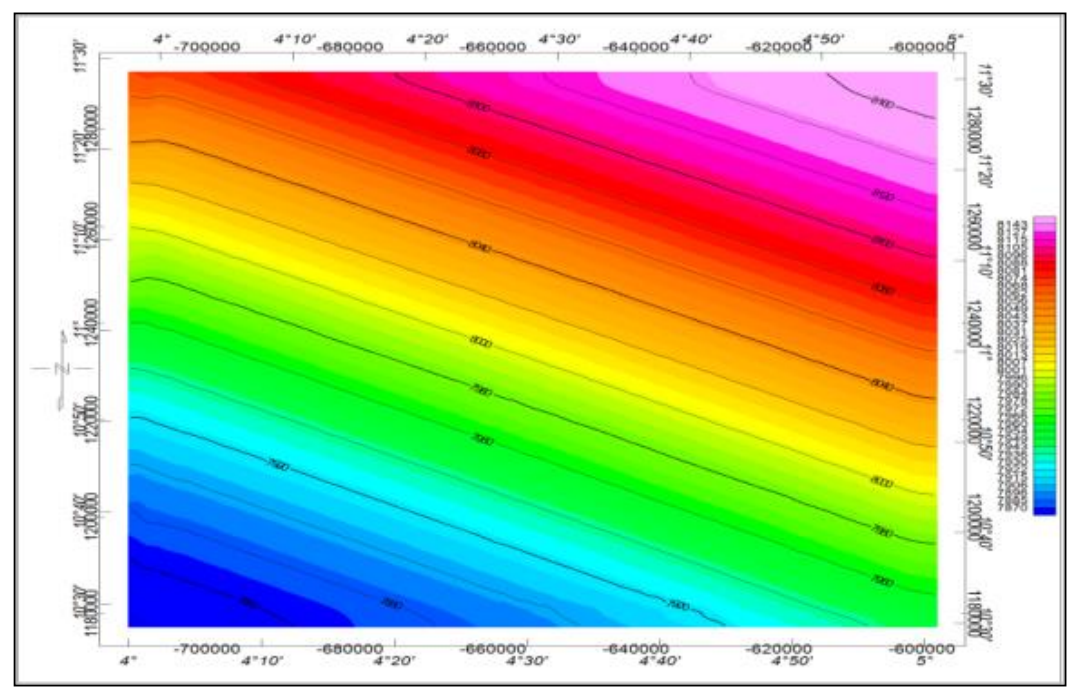

Fig-3.2: Regional Map of the Study Area

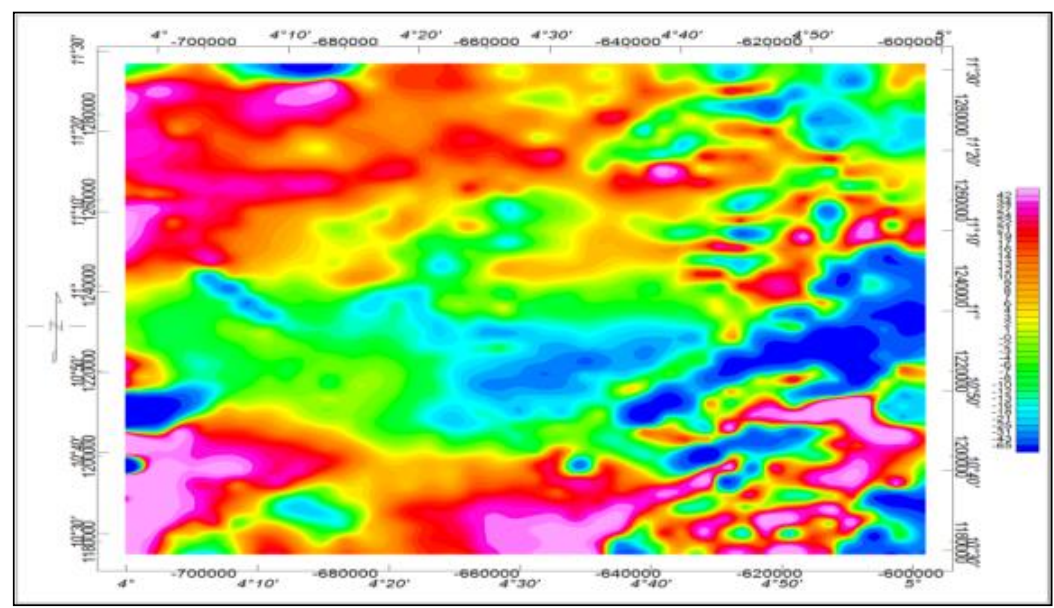

Fig-3.3: Residual Magnetic Intensity Map of the study area.

\section{Spectral Depth Analysis}

The result of the spectral analysis of the nine sections carried out in the survey area is shown in Table 1.

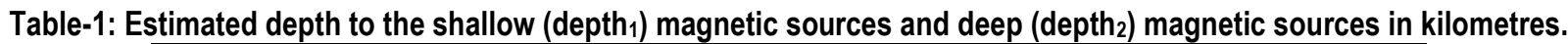

\begin{tabular}{|c|l|c|r|r|r|}
\hline Section & Sheet Name & Longitude & \multicolumn{1}{|c|}{ Latitude } & \multicolumn{1}{|c|}{$\mathbf{Z}_{\mathbf{1}}(\mathbf{k m})$} & $\mathbf{Z}_{2}(\mathbf{k m})$ \\
\hline A & Konkoso & 4.25 & 10.75 & 0.922 & 2.705 \\
\hline B & Yelwa & 4.75 & 10.75 & 0.773 & 2.601 \\
\hline C & Kaoje & 4.25 & 11.25 & 0.843 & 2.673 \\
\hline D & Shanga & 4.75 & 11.25 & 0.589 & 2.506 \\
\hline E & Konkoso/Yelwa & 4.50 & 10.75 & 1.169 & 2.840 \\
\hline F & Kaoje/Shanga & 4.50 & 11.25 & 1.249 & 3.111 \\
\hline G & Konkoso/Kaoje & 4.25 & 11.00 & 1.058 & 3.174 \\
\hline H & Yelwa/Shanga & 4.75 & 11.00 & 0.827 & 2.951 \\
\hline I & Konkoso, Yelwa & 4.50 & 11.00 & 1.010 & 2.824 \\
\hline
\end{tabular}

\section{Contour of Basement Depth}

The depth to basement contour map showed that the basement depth deepens from the northwestern part (NW) of the study area towards Kaoje until it attains a maximum depth of $3.174 \mathrm{~km}$ and there after rises towards the flanks. The Figure thus depicts a (NE-SW) a subbasinal structure between Kaoje and Shanga. The 3D surface plot of the basement depth Figure 5 clearly showed the aforementioned structure. 


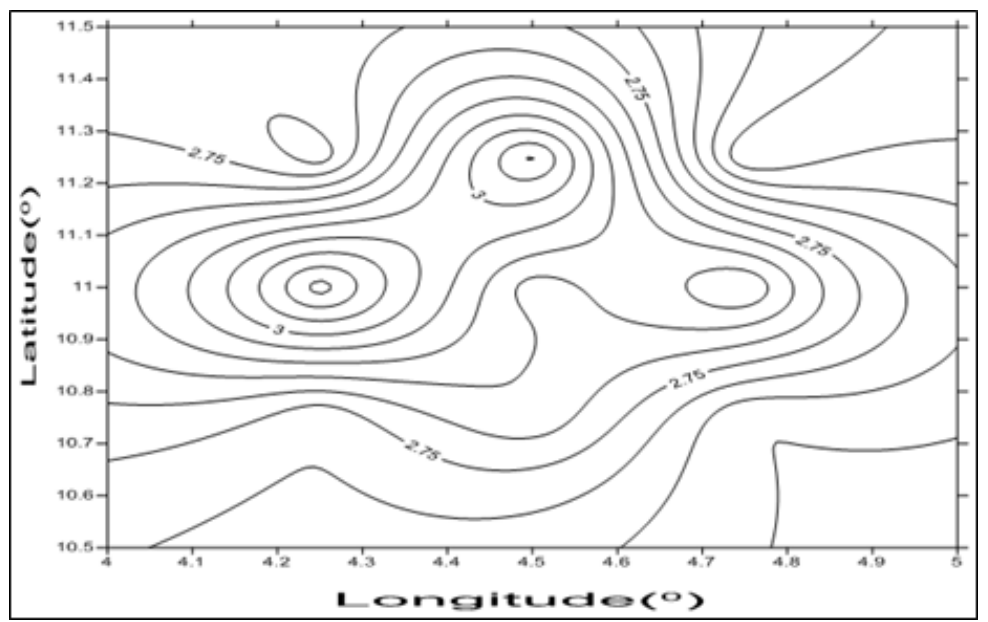

Fig-4.1: Contour map of the second layer depth (contoured at interval of $0.05 \mathrm{nT}$ )

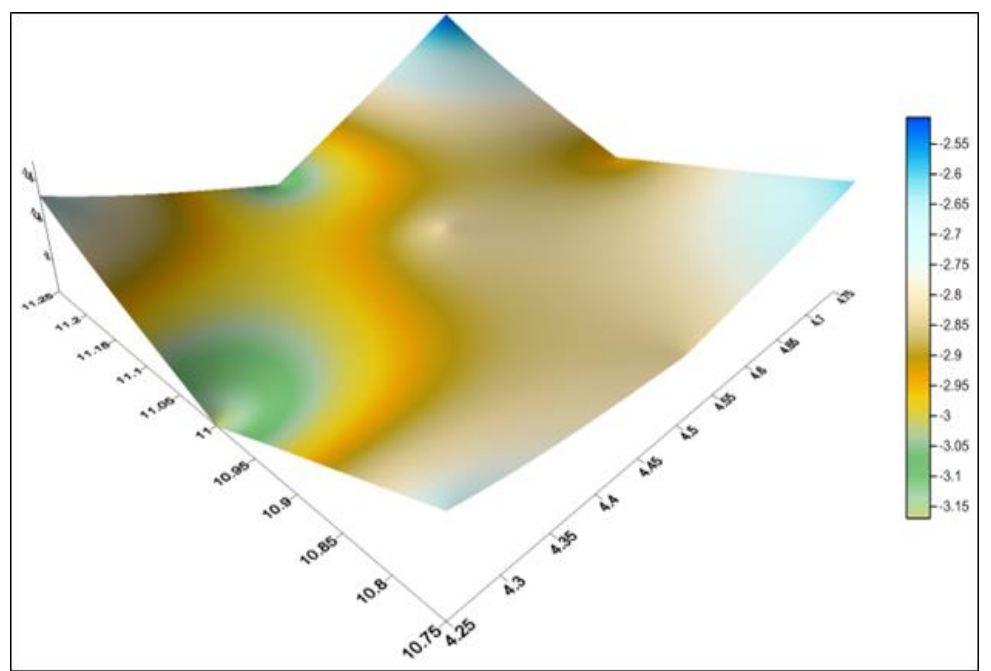

Fig-4.2: Surface plot Map of the second Layer Depth

\section{CONCLUSIONS}

The result obtained from this study using spectral analysis method shows that the study area has sedimentary thickness of about $3.174 \mathrm{~km}$. One important significance of this result is in its consideration of hydrocarbon prospect of the basin. If all other conditions for hydrocarbon accumulation are favourable, and the average temperature gradient of $1^{\circ} \mathrm{C}$ per $30 \mathrm{~m}$ which obtains in the Niger Delta is applicable then the maximum thickness of sediments to achieve the threshold temperature of $115{ }^{\circ} \mathrm{C}$ for the concealment of oil formation from organic remains [10] would be $2.3 \mathrm{~km}$. The result obtained shows that the prospect for hydrocarbon accumulation may be promising.

\section{RECOMMENDATIONS}

Several depressions or variations in thickness have been observed in some parts of the lower Sokoto Basin, particularly around Konkoso $(3.2 \mathrm{~km}$ ) Sheet 117 areas, these deeper sections of the study area sedimentary basin identified in this study, might be probable potential site for hydrocarbon deposits and is therefore recommended to be subjected to further investigation using other geophysical method such as seismic. Exploration of the Nigerian inland basins is worth given a push. Hydrocarbons if discovered and harnessed will increase the country's reserve and boost productivity. All these will have economic and strategic benefits for the country.

\section{REFERENCES}

1. Dobrin, M. B., \& Savit, C. H. (1960). Introduction to geophysical prospecting (Vol. 4). New York: McGraw-hill.

2. Kearey, P., Brooks, M., \& Hill, I. (2013). An introduction to geophysical exploration. John Wiley \& Sons.

3. Corell, L., \& Grouch, V. J. S. (1985). Mapping basement zones from magnetic data in the san juan basin; New Mexico: presented at the 52nd Annual International Meeting. Society for exploration geophysicists.

4. Hahn, A., Kind, E. G., \& Mishra, D. C. (1976). Depth estimation of magnetic sources by means of Fourier amplitude spectra. Geophysical Prospecting, 24(2), 287-306. 
5. Udensi, E. E., Osazuwa, J. B., \& Daniyan, M. A. (2001). Production of a composite aeromagnetic map of the Nupe Basin, Nigeria. J. Sci. Tech. Arid. Maths Educ, 3, 150-159.

6. Spector, A. (1968), Spectral analysis of aeromagnetic data. PhD Thesis, University of Toronto,Canada.

7. Spector, A., \& Grant, F. S. (1970). Statistical models for interpreting aeromagnetic data. Geophysics, 35(2), $293-302$.

8. Oppenheim, A. V., \& Schafer, R. W. (1975). Digital Signal Processing [by] Alan V. Oppenheim [and] Ronald W. Schafer. Prentice-Hall.

9. Kangkolo, D. E., \& Ojo, S. B. (1976). The influence of outlier points and their suppression in the determination of regional fields by polynomial fitting. In Proceedings of the 31s' Annual Conference of the Nigerian Mining and Geosciences Society.

10. Wright, J. B., Hastings, D. A., Jones, W. B., \& Williams, H. R. (1985). Geology and mineral resources of West Africa (Vol. 187). London:: Allen \& Unwin. 